\title{
Can I Trust You? Estimation Models for e-Bikers Stop-Go Decision before Amber Light at Urban Intersection
}

\author{
Jing Cai $\left(\mathbb{D},{ }^{1}\right.$ Jianyou Zhao $\left(\mathbb{D},{ }^{2}\right.$ Yusheng Xiang $\left(\mathbb{D},{ }^{3}\right.$ Jing Liu $\left(\mathbb{D},{ }^{2,4}\right.$ Gang Chen $\left(\mathbb{D},{ }^{1}\right.$ Yueqi Hu $(\mathbb{D}){ }^{2}$ \\ and Jianhua Chen $\mathbb{D i D}^{5}$
}

${ }^{1}$ School of Transportation Engineering, Chang'an University, Xi'an 710064, China

${ }^{2}$ School of Automobile, Chang'an University, Xi'an 710064, China

${ }^{3}$ Institute of Vehicle System Technology, Karlsruhe Institute of Technology, Karlsruhe 76131, Germany

${ }^{4}$ School of Mechanical and Electrical Engineering, Anhui Jianzhu University, Hefei 230601, China

${ }^{5}$ Transportation Information Center, China Academy of Transportation Sciences, Beijing 100029, China

Correspondence should be addressed to Jianyou Zhao; jyzhao@chd.edu.cn

Received 26 October 2020; Revised 16 November 2020; Accepted 13 December 2020; Published 24 December 2020

Academic Editor: Feng Chen

Copyright ( 2020 Jing Cai et al. This is an open access article distributed under the Creative Commons Attribution License, which permits unrestricted use, distribution, and reproduction in any medium, provided the original work is properly cited.

\begin{abstract}
Electric bike (e-bike) riders' inappropriate go-decision, yellow-light running (YLR), could lead to accidents at intersection during the signal change interval. Given the high YLR rate and casualties in accidents, this paper aims to investigate the factors influencing the e-bikers' go-decision of running against the amber signal. Based on 297 cases who made stop-go decisions in the signal change interval, two analytical models, namely, a base logit model and a random parameter logit model, were established to estimate the effects of contributing factors associated with e-bikers' YLR behaviours. Besides the well-known factors, we recommend adding approaching speed, critical crossing distance, and the number of acceleration rate changes as predictor factors for e-bikers' YLR behaviours. The results illustrate that the e-bikers' operational characteristics (i.e., approaching speed, critical crossing distance, and the number of acceleration rate change) and individuals' characteristics (i.e., gender and age) are significant predictors for their YLR behaviours. Moreover, taking effects of unobserved heterogeneities associated with e-bikers into consideration, the proposed random parameter logit model outperforms the base logit model to predict e-bikers' YLR behaviours. Providing remarkable perspectives on understanding e-bikers' YLR behaviours, the predicting probability of e-bikers' YLR violation could improve traffic safety under mixed traffic and fully autonomous driving condition in the future.
\end{abstract}

\section{Introduction}

In recent years, the transportation system has been undergoing huge change. Not only is the nonmotor vehicle characterized as one of the popular transportation modes in some Asian countries (i.e., China, Malaysia, and Thailand) [1], but also it is the widely used mode of transportation in developed countries (i.e., Australia, Sweden, and Germany) [1-3]. Cycling possesses plenty of advantages compared to other transportation modes, which is in terms of its flexibility, easy manoeuvrability, easy parking, lower cost, and convenience in congestion traffic [1]. In China, the transportation system has been undergoing huge change in recent years. Electric bicycle (e-bike) has increased dramatically and constituted about $34 \%$ of all transportation modes in China, and the number of e-bikes has been in excess of 250 million in 2018 [4]. Without a doubt, with the growing popularity of e-bike, many countries have experienced a tremendous growth in traffic crashes involving e-bike. Because e-bike is defined as nonmotor vehicle by most countries in the world, e-bikers are not required to have driving license which may cause them to overestimate their cycling technique. Due to the unskilled cycling performance and being not protected by any metal structures, the casualties of e-bikers were about 32579 in traffic accident from 2016 to 2017 [4, 5]. Moreover, e-bike crashes were composed of $70 \%$ Chinese nonmotor traffic accidents in 2015 [4]. Intersection is one of the most dangerous parts in road 
network. Particularly, intersection is one of the most dangerous parts in road network since statistics show that the vast majority of accidents occurred at intersection [6]. Signal violation including red-light running (RLR) and YLR could be the main reasons behind more than $60 \%$ of fatal crashes involving nonmotor vehicles in intersection [7]. Based on motor vehicle-oriented perspectives in road networks design, the signal indications are not supposed to fit nonmotor vehicles. Because of the different performance between motors and nonmotors, the complicated decision-making process for e-bikers at the beginning of amber light at intersection may incur a rear-end collision for the inappropriate stop-decision (emergency braking) or a right-angle collision for the inappropriate go-decision (yellow-light running). It is clear that those frequent inappropriate decisions could have negative effects not just on e-bikers' safety but also on other road users, especially on self-driving vehicles. However, although a series of studies have shown the prediction models for the behaviours of e-bikers during the red light, the research about the YLR behaviours of e-bikers is still a research gap. Therefore, it is indispensable to devote efforts to find out the contributing factors associated with e-bikers' YLR violation at the beginning of amber light to improve traffic safety under mixed traffic and fully autonomous driving condition in the future.

Amber light plays a crucial role in the efficiency and safety of a signalized intersection. Stop-go decision is required to make by drivers when they face the beginning of amber light. Gaizs et al. proposed the drivers' stop-pass model defined as Gazis-Herman-Maradudin model (GHM) [8]. Following Gaizs's research, many researchers studied drivers' stop-go decision in the signal change interval. Several lines of studies suggested that the likelihood of YLR increases when the vehicle has a high speed at the beginning of amber light [9-15]. It is now well established from a variety of studies that critical crossing distance (CCD) significantly impacts on drivers' stop-go decision $[9,10,12-14,16]$. These studies reported that a vehicle has shorter CCD, and drivers are more likely to run against the amber light signal. Amer et al. and Lu et al. showed that the changes of vehicle's acceleration rate also have significant impacts on drivers' YLR violation when drivers approach to the intersection during yellow phase $[10,11]$. In addition, drivers' stop-go decision at the beginning of amber light is not a simple function of vehicles' operation characteristics, but also it depends on various driver demographics. Research studies developed by Rakha et al., Campisi et al., and Savolainen found that the propensity of YLR for female drivers is vastly lower than male individuals [17-19]. Compared to young- and middle-age groups, the old-age drivers are with propensity to stop at the beginning of amber light [17]; however, the effect of age on drivers' YLR behavior is not consistent. Savolainen found that young- and middleage male drivers are the most likely to stop at the signal change interval among all participants in their experiment [19].

The existing researches explored two typical types of e-bikers' signal violation behavior, i.e., e-bike riders' RLR and YLR. First, many researchers focused on the effects of contributing factors which may have influence on e-bikers' RLR violation. Many studies examined the demographic factors associated with e-bikers' RLR behavior. There is a consensus that male riders have higher risk propensity to cross against the red indications than female e-bikers $[20,21]$. The age of e-bikers has been extrapolated to be a significant variable for estimating their RLR behaviors. Young-age riders are more inclined to running the red-light, and the old e-bikers have lower likelihood of RLR than the young- and middle-age ones. In terms of psychological factors, Yang et al. and Tang et al. revealed that attitude and perceived behavioral control are significant predictors for the intention of RLR behavior [22, 23]. A number of research studies have identified a link between e-bikers' RLR behaviors and environment factors. Previous studies on the number of riders waiting behind the stop mark have identified that the more riders wait behind the stop mark for next green light, the less riders cross against the red light $[24,25]$. Mei et al. and Yan et al. have shown that the RLR rate for e-bike is higher in off-peak hours in which the volume of motor vehicles is lower than that in peak hours $[25,26]$. Many studies have explored the relationship between the infrastructure of intersection and the e-bike riders' RLR behaviours. There is evidence that nonmotorized lanes separated from vehicle lanes $[3,20]$, the PCSD infrastructure [27], and sunshields [28] are effective in preventing e-bike riders' RLR behaviours.

In addition, with respect to e-bikers' YLR behaviours, Tang et al. reported that the potential time (PT) is the dominant factor to explain the stop-go decision for e-bikers. PT is the time to stop mark when e-bikers make a go-decision without changing their initial approaching speed [29]. Various researchers analyzed the environment factors contributing to e-bikers' decision of YLR. Dong et al. focused on the effects of flash green signal on the YLR violation and they found that flashing green signals not just almost eliminate the DZ but also enlarge the OZ for e-bikers [30]. Tang et al. concluded that the green-light time and intersection's form are the most significant factors to e-bikers' GR near-violation which is also called YLR violation [31].

In terms of e-bikers' signal violation in modeling identification, many analytical methods have been established to solve this problem. Logistics regression is widely utilized to analyze the RLR behavior for e-bikers [20, 28, 32, 33]. Yang et al. and Mei et al. developed survival analysis model to investigate e-bikers' risky crossing behaviours [21, 25]. The theory of planned behavior (TPB) model was used to predict for e-bikers' intention of RLR in these studies conducted by Yang et al. and Tang et al. [22, 23]. A Hidden Markov Driving model proposed by Dong et al. and Li et al. $[30,34,35]$ was used to explain the YLR behaviour of motor drivers and e-bikers. An integrated regression analysis developed by Tang et al. was used to explain the probability of e-bikers' YLR behaviours [31]. Numerous researchers have tried to use many methods identifying the factors influencing e-biker's signal violation. However, the violation behaviour might occur under distinct conditions and influencing by other unobserved influential factors of individuals, which may lead to omitting the 
unobserved heterogeneity and making the wrong analysis for the results $[24,36]$. To provide some insights into this problem, some researchers established random parameter logit model (RPLM) which is also called mixed logit model $[19,24,37]$ to eliminate the effects of unobserved heterogeneity. Wang et al. identified variables contributing to RLR behavior of pedestrians and e-bikers using the RPLM [24]. Zheng et al. established a random coefficient logistics model to identify factors associated with the violation of pedestrian and cyclists on the Brooklyn Bridge promenade [36]. And the RPLM was used to investigate the effect of factors in other traffic safety researches [38, 39]; for instance, the studies analyzed the injury severity for drivers [40-42].

The aim of our paper is to analyze the factors contributing to e-bikers' YLR violation. Based on the natural observation data, two analytical logit models (i.e., a base logit model and a random parameter logit model) were established to explain the effects of contributing factors. There are three advantages of this study. First, we analyzed the impact factors, where the e-bikers' personal characteristics and their operating characteristics are included, on e-bikers' YLR violation using massive amount of crossing trajectories in the case of signal change interval, by extracting the real-time data from high-resolution event-based recorded data. Secondly, we first classified e-bikers' YLR behaviours in terms of how many times e-bikers changed his/her stop-go decision in $6 \mathrm{~s}$ before the end of green light into normal yellow-light running (NYLR) and aggressive yellow-light running (AYLR) and also classified e-bikers' YLS behaviours into normal yellow-light stopping (NYLS), aggressive yellowlight stopping (AYLS), and conservative yellow-light stopping (CYLS), which has clearly shown the decision-making process for e-bikers in the signal change interval. Thirdly, the use of random parameter logit model (RPLM) in this study has advantages in that it can account for the unobserved heterogeneity which is likely to present the e-bikers' individuals' differences.

The structure of rest paper is as follows. The data collection process is presented in Section 2, in which a method is also developed to categorize YLR and yellow-light stopping (YLS) e-bikers into different types according to the changes of acceleration rate during 6-second green light before the beginning of amber light. Section 3 briefly introduces the two logit models. In Section 4, the statistics analysis of observation, the analysis of different types for YLR and YLS behaviours, and the results of the two models are presented. Section 5 gives a discussion of the model estimating results. Finally, concluding remarks and the perspectives for further research are given.

\section{Data Collection and Process}

2.1. Site Selection and Description. It has been proved that direct observation can provide quite useful information to study road users' behavior by previous researches $[11,29,30,36]$. In this study, a natural observation was conducted in Xi'an, China, which has 10 million residents, and the ownership of e-bike has been over 3 million [4]. A typical four-leg intersection located in Huancheng South
Road, which is the major corridor connecting east and west of Beilin district, and Wenyi North Road (H-W intersection) was selected for natural observation. $\mathrm{H}-\mathrm{W}$ intersection is with the following characteristics. (a) An exclusive nonmotorized lane exists in upstream of the intersection, which could separate the nonmotors including e-bikes and regular bikes from motors in order to reduce the interactive impact. (b) The landscape trees do not exist on the side of nonmotorized lane, which may help clearly observe e-bikers' crossing behaviour in signal change interval. (c) A countdown signal device (CSD) is installed in $\mathrm{H}-\mathrm{W}$ intersection, all motor drivers and cyclists who are approaching the intersection in the same direction should obey the CSD timer. A traffic signal phase in which a $6 \mathrm{~s}$ countdown green signal is displayed at the end of green-light and a $3 \mathrm{~s}$ amber light signal following this countdown signal is used in this intersection (the traffic light phase at $\mathrm{H}-\mathrm{W}$ intersection is shown in Figure 1). (d) H-W intersection has a moderate e-bike traffic volume that does not cause the traffic jam and the e-bikers could smoothly clear the intersection without queueing.

2.2. Data Collecting. The main equipment used in this natural observation were an unmanned aerial vehicle (DJI Inspire 1) and a video camera (Sony FDR-AX45) to obtain high-resolution videos of e-bikers' stop-go decision-making process in signal change interval. In this natural observation, a 2-hour video was collected during weekday's morning and evening peak hours under good weather conditions for 2 weeks in October 2019; i.e., totally we recorded 20-hour tapes. To avoid buses and vehicles' crossing behaviours hindering e-bikes' crossing trajectory in the videotape, the UAV hovered for an altitude of $50 \mathrm{~m}$ over the nonmotorized lane located in upstream intersection and adjusted the lens angle of the camera to clearly record the riders' entire crossing process and the traffic signal indications (the first step shown in Figure 2). And the other synchronized camera was mounted on the telegraph poles that were located in the roadside of the intersection, to avoid being spotted by e-bikes and consequently causing their crossing behaviours changes. The lens angle of this camera was pointed towards the riders to obtain their detailed personals (the first step shown in Figure 2). These two cameras' time parameter was set identically and a synchronous remote control was used, which made them synchronize temporally and spatially to record e-bikers' crossing behaviours.

2.3. Data Processing. A data processing framework of this study is briefly presented in Figure 2. All the e-bike riders who entered the scope of the cameras and crossed the intersection were recorded; however, only the e-bikers who crossed straight through the intersection in the signal change interval were coded. Right-turn and left-turn e-bikers were excluded since their crossing trajectories may be hindered by turning motor vehicles.

Using two synchronized cameras with different perspectives, we obtained two temporally and spatially synchronous tapes. After that, we manually matched, 


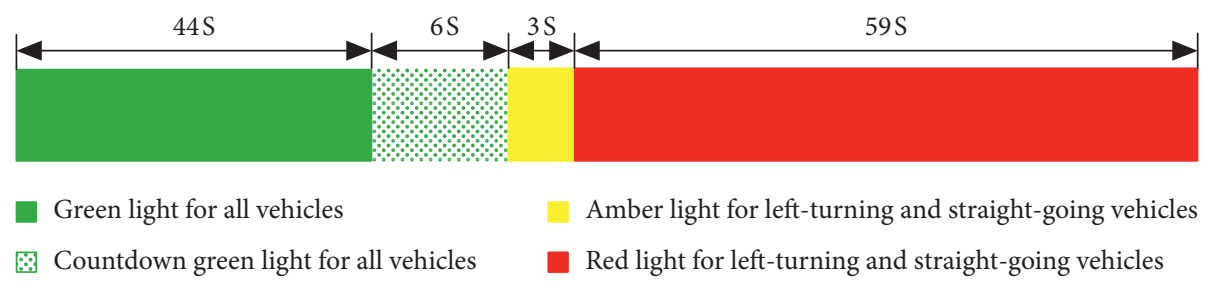

Figure 1: Traffic light phase at $\mathrm{H}-\mathrm{W}$ intersection.

numbered, and then recorded the target e-bikers according to the identical schedule and the e-bikes' appearance in two videos (the third step shown in Figure 2). Utilizing a trajectory analysis software Tracker, we extracted the target e-bike position and trajectories in the period of 9 seconds before the light turns red, including 3 seconds of amber light and the last 6 seconds of green light. As the input for the trajectory software, we measured the road traffic marking in the middle of the intersection as a reference to evaluate the objects' sizes in the videos, so that the software can automatically extract the $X$ and $Y$ data of e-bikes position in real time. Obviously, the calculations for meaningful information of e-bikes were described in equations (1)-(3). Equation (1) calculates the displacement of the e-bike. The following equation calculates the displacement of e-bike in frame $i$ denoted as $S_{i}(\mathrm{~m})$ :

$$
S_{i}=\sqrt{\left(x_{i}-x_{i-1}\right)^{2}+\left(y_{i}-y_{i-1}\right)^{2}},
$$

where $x_{i}$ is the displacement of e-bike on the $X$-axis in frame $i, y_{i}$ is the displacement of e-bike on the $Y$-axis in frame $i$, and $i$ is the number of the frame.

The following equation is used to calculate the instantaneous speed denoted as $v_{i}(\mathrm{~m} / \mathrm{s})$ :

$$
v_{i}=\frac{s_{i}}{t},
$$

where $t$ is the time length of frame $i$.

The following equation calculates the instantaneous accelerated speed denoted as $a_{i}\left(\mathrm{~m} / \mathrm{s}^{2}\right)$ :

$$
a_{i}=\frac{v_{i}}{t}-\frac{v_{i-1}}{t}=\frac{s_{i}-s_{i-1}}{t^{2}} .
$$

Meanwhile, the data related to e-biker's personalities, including gender, estimated age group, and e-bike type, were labelled according to the appearance of e-bikes and riders from the videotape by two students, who were trained to be familiar with common e-bike models and learned the standards for classifying the e-bikers' age group. In order to avoid data recording mistake, recoding reliability was calculated by Cohen's kappa for categorical variables and intraclass correlation for continuous variables. All the coefficients ranged from 0.81 to 0.98 , which ensured the reliability of extracting process.

The possible contributing factors (independent variables) were including gender (GEN), established age group (AGE), vehicle type (VT), the number of acceleration rate changes (NA), approaching speed (AS), and critical crossing distance (CCD). The details of independent variables are presented in Table 1. Three-category variables, namely, AGE and NA, were changed to two dummy variables for calculating BLM and RPLM, respectively. The old-age group and the e-bikers with acceleration rate change once time group were considered as the base variables; other age groups and times of acceleration rate change groups have been incorporated in the models as dummy variables. The variable AGE was converted into two dummy variables. The first dummy variable was young vs. old with 0 denoting the young and 1 denoting the old ones. The second dummy variable was middle-age vs. old with 0 denoting the middle-age riders and 1 denoting the old individuals. And the variable acceleration rate change once time was denoted 1 , while without acceleration rate change and the acceleration rate change more than 2 times were denoted 0 in the two dummy variables, respectively.

\subsection{Classification of Stop-Go Decision-Making Process.} Based on the Chinese Road Traffic Safety Law [43], we define the yellow-light running behaviour as that instead of stopping behind the stop mark at the beginning of amber light; the e-bikers continue going through the stop mark. After collecting the e-bikers' crossing trajectory data, YLR riders can be easily identified. The identifying reliability was calculated by Cohen's kappa coefficient and the value of coefficient is 0.94 , ensuring the reliability of identifying process.

2.4.1. Yellow-Light Running Behaviour Categorization. As a consequence of the e-bikes' manual operation power system, the acceleration rate is positive when e-bikers continue going forward. On the contrary, the acceleration rate is negative when e-bikers decide to stop. It was proved by previous study that the operating characteristics may reflect the physiological characteristics of drivers during the actual driving process [44]. The e-bikers' stop-go decision-making process could be precisely presented by the real-time acceleration rate. In this study, YLR behaviour is classified into normal yellow-light running (NYLR) and aggressive yellowlight running (AYLR), based on how many times e-bikers changed their stop-go decision in the last 6 seconds of green light. NYLR behaviour is defined if the riders make a decision to speed up through the stop mark after observing that the countdown green light began to flash but fail to pass it before the beginning of amber light. This category is shown in Figure 3(a), the speed increased due to the acceleration rate increase and maintained positive as the e-bikers made a go-decision to pass through the stop mark before the 


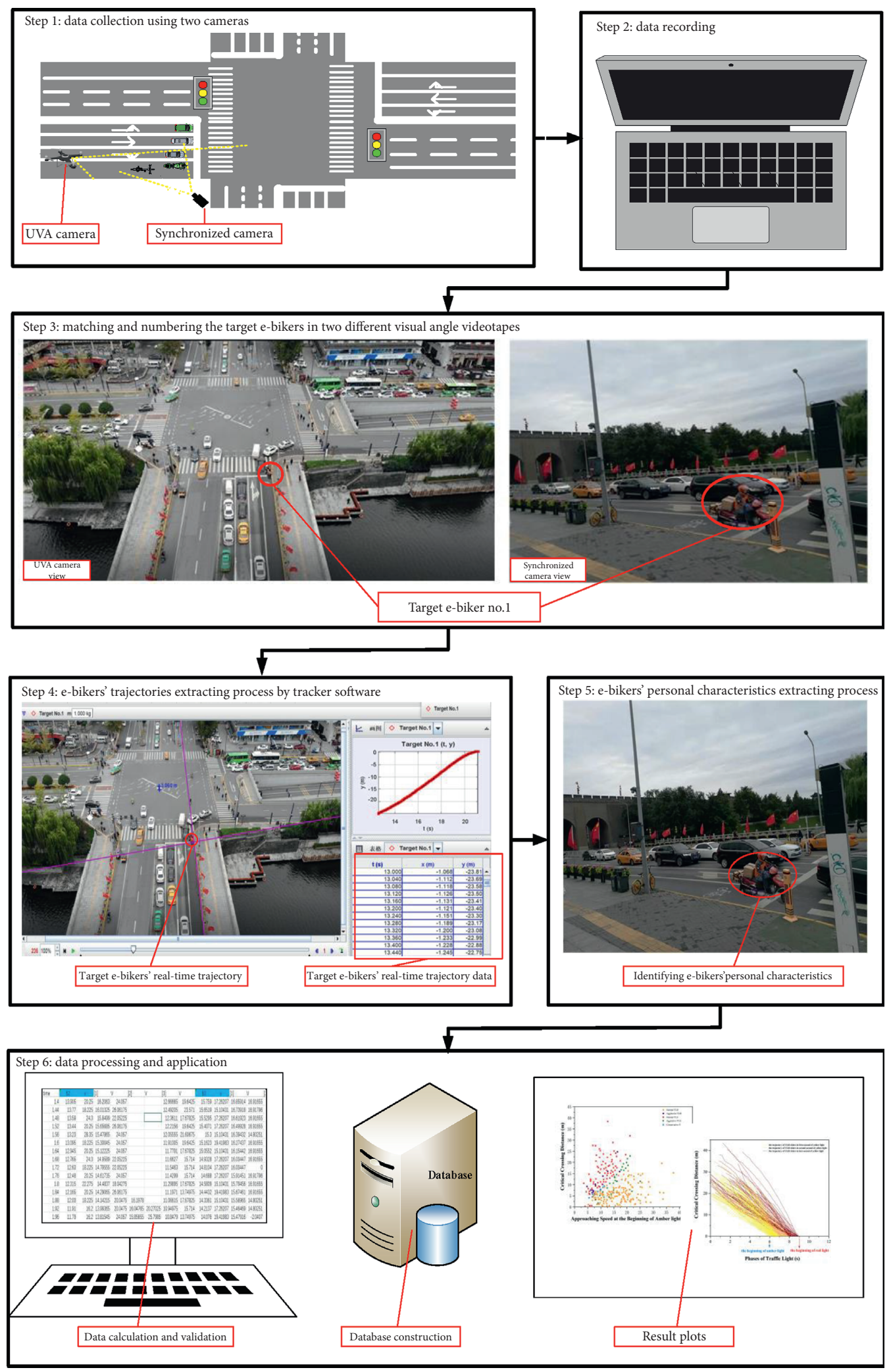

Figure 2: Data processing framework.

beginning of amber light. AYLR referred to the riders who firstly decided to decelerate but made a second decision to accelerate to cross through the stop mark; however, they failed to pass it before the beginning of amber light. Figure 3(b) presented the speed and acceleration/deceleration rate of typical types for AYLR violation. It can be seen 
TABLE 1: Definition of variables coded.

\begin{tabular}{|c|c|c|}
\hline Variable & Description & Coding value \\
\hline \multirow{2}{*}{ GEN } & Male & 0 \\
\hline & Female & 1 \\
\hline \multirow{3}{*}{ AGE } & Young-age group $(<30)$ & 0 \\
\hline & Middle-age group $(30-50)$ & 1 \\
\hline & Old-age group $(>50)$ & 2 \\
\hline \multirow{2}{*}{$\mathrm{VT}$} & Bicycle electric bike & 0 \\
\hline & Scooter electric bike & 1 \\
\hline \multirow{3}{*}{ NA } & 0 changes & 0 \\
\hline & More than 2 changes & 1 \\
\hline & 1 change & 2 \\
\hline AS & The speed of e-bike when it approached intersection at the beginning of amber light. & The real-time value \\
\hline CCD & The distance of e-bike away from stop mark at the beginning of amber light. & The real-time value \\
\hline
\end{tabular}

AGE: estimated age group. Using estimated age group could be effective to extract e-bikers' individual information. The groups were divided into young-age riders $(<30)$, middle-age riders (30-50), and old-age riders ( $>50)$ reported by Wu et al. [7]. VT: vehicle type. Bicycle e-bike can ride the pedal to provide power for going forward, while the scooter e-bike's power is only provided by electromotor. NA: number of acceleration rate changes. The number of times that acceleration rate changes from positive to negative, or from negative to positive.
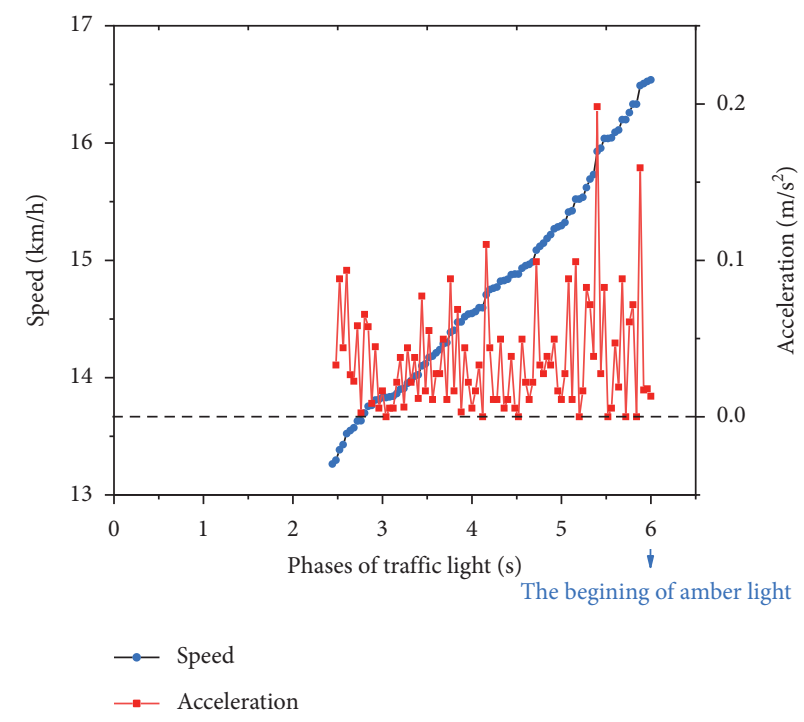

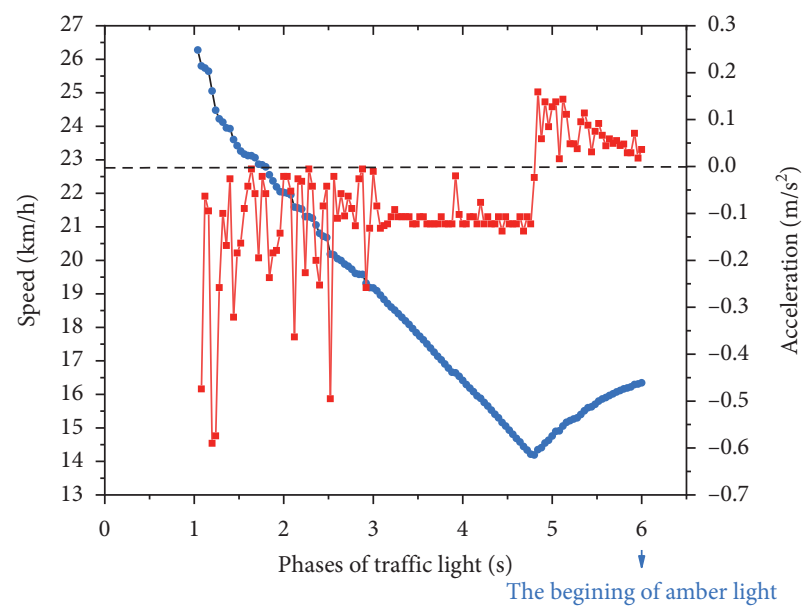

$\rightarrow$ Speed
$\rightarrow$ Acceleration

(a)

(b)

FIgURE 3: Typical approaching speed and acceleration rate profile of NYLR and AYLR e-bikers.

that the speed dropped off due to the acceleration rate decrease below zero when e-bikers made a stop-decision at the beginning of countdown green light, and then the speed distinctly increased with the increase of acceleration before the beginning of amber light. We conjecture that they may change their initial idea and decide to pass through the intersection based on their newly gathered circumstance information, such as critical crossing distance and the volume of nonmotors and motors.

\subsubsection{Yellow-Light Stopping Behaviour Categorization.} Yellow-light stopping (YLS) behaviour is defined as that riders stopped in appropriate position, i.e., behind the stop mark, before the end of amber light signal. The decisionmaking process distinguished three different types of YLS behavior, i.e., normal yellow-light stopping (NYLS), aggressive yellow-light stopping (AYLS), and conservative yellow-light stopping (CYLS). NYLS is the behaviour that e-bikers initially decided to stop slowly and could stop behind the stop mark before the onset of red light. Figure 4(a) shows the speed and deceleration rate of typical types for NYLS behaviour. It is clear that with the acceleration rate decreasing below zero, the speed of e-bike gone down almost to zero before the beginning of red light. Defined as AYLS, the behaviour is considered as that riders who decided to pass through stop mark at the onset of the countdown green light but later they changed their initial decisions from passing to stopping caused by the changing environment or other reasons. Figure 4(b) shows the opposite trend to Figure 3(b). The speed increased with the increase of acceleration rate at the beginning of countdown 


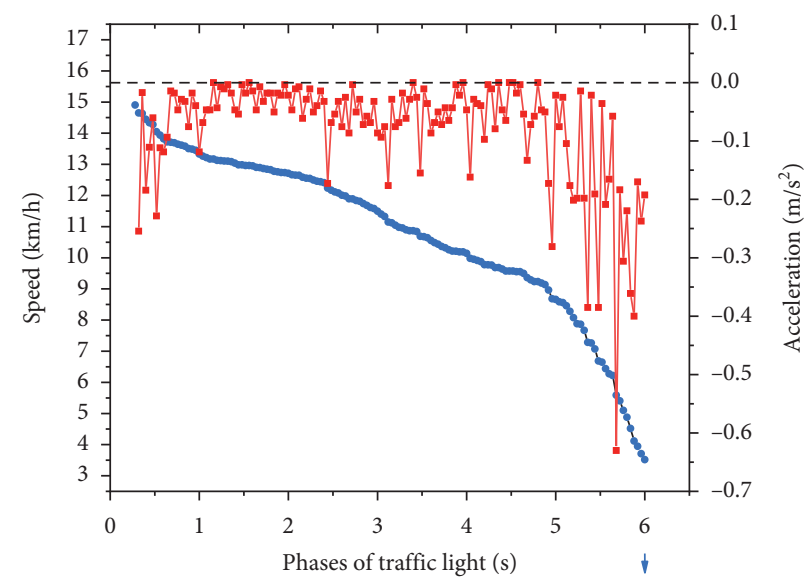

The begining of amber light

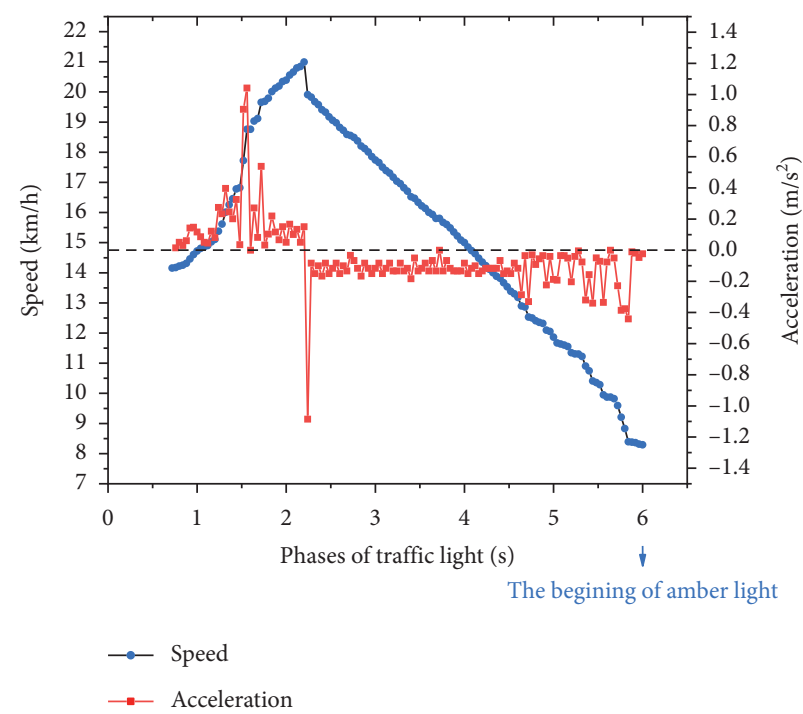

(b)

(a)

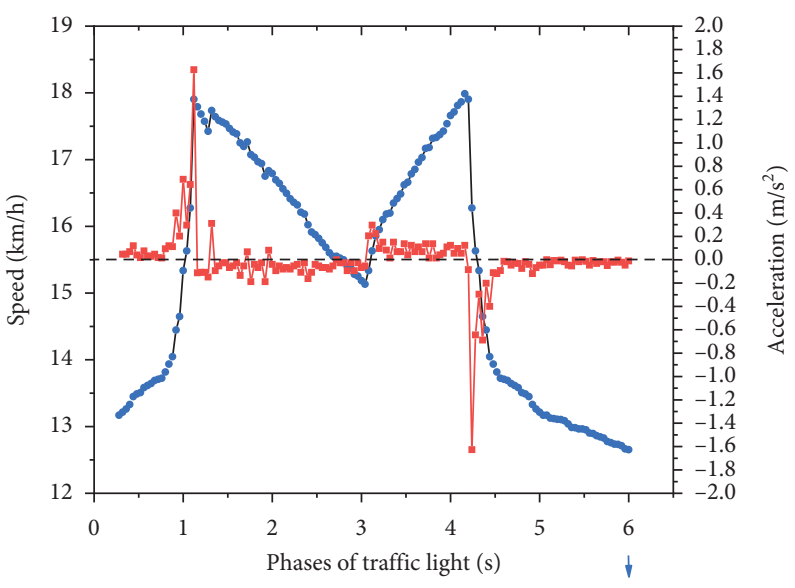

The beginning of amber light

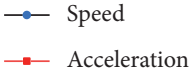

(c)

FIgURE 4: Typical approaching speed and acceleration rate profile of NYLS, AYLR, and CYLS e-bikers.

green light, and then it decreased for the acceleration rate decreasing below zero before the beginning of amber light. CYLS can be described as the behaviour that the e-bikers made multiple go-stop decisions from the onset of countdown green light to the end of it, but they finally stopped behind the stop mark. Figure 4(c) displays the speed and acceleration rate for typical types for CYLS behaviour. It can be seen that the speed of e-bike fluctuated over the change of acceleration rate, which happened because the e-bikers made multiple stop-go decisions during the countdown green-light time.

\section{Methodology}

Logistics regression has been widely applied to analyze the risk behaviour of road users in previous researches, especially to examine the factors contributing to RLR and YLR illegal behaviour $[4,20,28,32,33,45]$. In this study, we developed two logit models, namely, a base logit model and a random parameter logit model, to analyze the e-bikers' behaviour with respect to the stop-go decision when they were facing the signal change from green to yellow. In our two logit models, $Y=1$ denoted YLR e-bikers and $Y=0$ denoted YLS e-bikers. The outcome of rider $i$ 's decision to go through the stop mark at the beginning of amber light represented as $Y_{i}$ is shown in the following equation:

$$
Y_{i}=\beta \mathbf{X}_{i}+\varepsilon_{i}
$$

where $\beta$ is a vector of estimable regression parameters; $\mathbf{X}_{i}$ is a vector of the observed variables which may affect the YLR behaviour; and $\varepsilon_{i}$ is an error term.

The probability of the e-biker $i$ 's infringement of the amber light was obtained from the base logit model in the following equation: 


$$
p_{i}=\left(y_{i}=1 \mid x_{0}, x_{1}, \ldots, x_{n}\right)=\frac{\operatorname{EXP}\left(\beta \mathbf{X}_{i}\right)}{1+\operatorname{EXP}\left(\beta \mathbf{X}_{i}\right)} .
$$

In this base logit model, $p_{i}$ is the probability that YLR events occurred, and $\beta_{i}$ is the corresponding coefficient of $x_{i}$ estimated by the method of maximum likelihood. However, the base logit model has drawbacks which cannot analyze the potential effects of unobserved heterogeneity in riders' individual characteristics and cannot allow unobserved environment factors of utility to be correlated. All these random effects may result in erroneous parameter estimation and prejudices in estimation of the model, and the heterogeneity (i.e., some riders are prone to stop at the amber light interval and have lower risk propensity) may damage the Independence from Irrelevant Alternatives (IIA) assumption $[15,19,24,37,40,46]$. To obtain an accurate estimation of variables, we proposed a random parameter logit model to analyze e-bikers' YLR behavior. The rider YLR propensity function was proposed in the following equation:

$$
T_{i}=\beta_{i} \mathbf{X}_{i}+\varepsilon_{i}
$$

where $\beta_{i}$ is the special parameter vector for the final decision of rider $i$ which may vary across observed individual riders.

As mentioned above, substituting equation (6) into equation (5), the random parameter logit model was established as follows:

$$
p_{i}=\left(y_{i}=1 \mid x_{0}, x_{1}, L x_{n}\right)=\int_{x} \frac{\operatorname{EXP}\left(\beta_{i} \mathbf{X}_{i}\right)}{1+\operatorname{EXP}\left(\beta_{i} \mathbf{X}_{i}\right)} f\left(\beta_{i} \mid \phi\right) \mathrm{d} \beta_{i},
$$

where $f\left(\beta_{i} \mid \phi\right)$ is the probability density function of $\beta_{i}$, and $\phi$ refers to a vector of parameters for the function (mean and variance).

The probability of the rider $i$ 's infringement of the amber light estimated by equation (7) cannot be calculated exactly because of involving a multidimensional integral which is not close to solution. Quasirandom numbers generated by Halton, also called Halton's draws, were proved to be an efficient alternative to pseudorandom numbers by Bhat and Train [37]. In this study, we used Halton's draws to draw the values of $\beta_{i}$ from $f\left(\beta_{i} \mid \phi\right) .200$ Halton draws, the number of Halton draws, were used to calculate the accurate parameter estimation which has been proved to be a sufficient number in prior studies $[19,24,46]$. In addition, all parameters were assumed to follow normal distribution as presented in Wang and Savolainen's studies [19, 27].

Furthermore, the goodness-of-fit statistics measure Akaike Information Criterion (AIC) was used for model comparison. The value of AIC was calculated in the following equation:

$$
\mathrm{AIC}=-2 \mathrm{LL}+2 p,
$$

where $L L$ is the log-likelihood at convergence for the estimated model and $p$ is the number of parameters in the model.

\section{Results}

4.1. Description Statistics of e-Bikers' Yellow-Light Running and Yellow-Light Stopping Behaviour. A total of 297 first-tostop and first-to-go e-bikers (186 e-bikers with YLR behavior and 111 e-bikers with YLS behaviors) approaching the intersection during the signal change interval were observed in $20 \mathrm{~h}$ high-resolution videos. The following e-bikers were excluded to eliminate the influence of the leading e-bikes in the queue on their crossing behaviours.

The trajectories of YLR e-bikers are shown in Figure 5. The majority of YLR behavior (accounting for more than $70 \%$ of all YLR e-bikers) occurred during the early stages (i.e., the first and second) of an amber light. All the 297 observed e-bikers, divided into different types of YLR and YLS according to their decision-making process, were summarized as follows.

As shown in Tables 2 and 3, the descriptive statistics for the number of e-bikers' infringement behaviour in different groups were tested by chi-square test. Firstly, male e-bikers were prone to have YLR violation than female e-bikers (128 vs. $58, p<0.01)$. In addition, the riders who rode bicycle e-bikes were less likely to have YLR behaviour than the riders who rode scooter e-bikes (136 vs. 50, $p<0.05)$. However, there was no statistical difference in the number of YLR in different age groups $(p=0.235)$.

As shown in Table 2, the overall proportion of YLR e-bikers who made one decision to run against the amber light, also called normal yellow-light running riders, was 93\%. The majority of YLR e-bikers did a go-decision and did not change their initial decisions when they were facing the appearance of countdown green-light indications; only $7 \%$ of e-bikers modified their initial stop-decisions to go-decisions. A chi-square test was used to analyze the number of different YLR types' behaviours in different groups of e-bikers' personal characteristics. The occurrence rate of female NYLR riders was slightly greater than that of male NYLR riders (94.8\% vs. $92.2 \%, p<0.001)$, while the rate of male AYLR riders was larger than that of female AYLR riders $(7.8 \%$ vs. $5.2 \%, p<0.001)$. These results suggested that a large percentage of female YLR e-bikers decided to cross through the stop mark and did not change their initial godecision after observing the onset of countdown green-light indications and that male YLR riders were more likely to change their initial stop-decision to continue crossing through the stop mark to run against the amber light. Based on the statistically significant difference, scooter e-bikers were more likely to have AYLR behaviours (7.4\% vs. $6 \%$, $p<0.05)$. A higher proportion of NYLR e-bikers and a lower proportion of AYLR e-bikers were observed in the old-age group than the young- and middle-age riders $(100 \%$ vs. $93.9 \%$ and $87.7 \%, 0 \%$ vs. $6.1 \%$ and $12.3 \%$ ); however, the difference cannot be observed in the number of different YLR types for different age groups from the results of chisquare test $(p=0.179)$. 


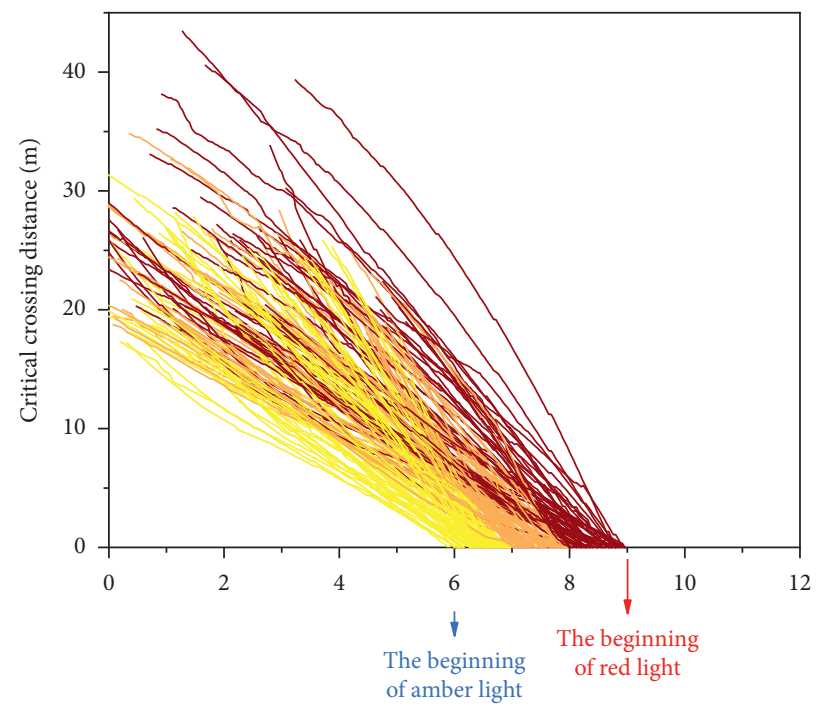

Phases of traffic light (s)

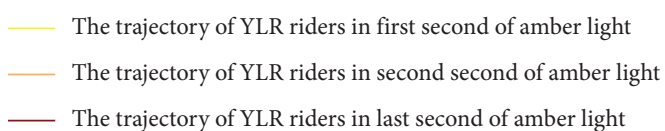

FIGURE 5: YLR e-biker's trajectories at the intersection.

TABLE 2: Statistics of yellow-light running behaviour by each subcategory.

\begin{tabular}{lcc}
\hline & Number of YLR riders & Aggressive running \\
Running behavior type & Normal running & $7.8 \%(10 / 128)$ \\
\hline Gender & & $5.2 \%(3 / 58)$ \\
Male & $92.2 \%(118 / 128)$ & $6.1 \%(6 / 98)$ \\
Female & $94.8 \%(55 / 58)$ & $12.3 \%(7 / 57)$ \\
\hline Age group & & $0 \%(0 / 31)$ \\
Young & $93.9 \%(92 / 98)$ & \\
Middle-age & $87.7 \%(50 / 57)$ & $6.0 \%(3 / 50)$ \\
Old & $100 \%(31 / 31)$ & $7.4 \%(10 / 136)$ \\
\hline Vehicle type & & $7.0 \%(13 / 186)$ \\
Bicycle-style electric-bike & $94.0 \%(47 / 50)$ & $92.6 \%(126 / 136)$ \\
Scooter-style electric-bike & $93.0 \%(173 / 186)$ & \\
\hline Overall & & \\
\hline
\end{tabular}

TABLE 3: Statistics of yellow-light stopping behaviour by each subcategory.

\begin{tabular}{lccc}
\hline & \multicolumn{2}{c}{ Number of YLS riders } & \\
Stopping behavior type & Normal stopping & Aggressive stopping & Conservative stopping \\
\hline Gender & $54.5 \%(24 / 44)$ & $43.2 \%(19 / 44)$ & $2.3 \%(1 / 44)$ \\
Male & $76.2 \%(51 / 67)$ & $11.9 \%(8 / 67)$ & $11.9 \%(8 / 67)$ \\
Female & & & \\
\hline Age group & $28.6 \%(6 / 21)$ & $57.1 \%(12 / 21)$ & $14.3 \%(3 / 21)$ \\
Young & $78.3 \%(54 / 69)$ & $14.5 \%(10 / 69)$ & $7.2 \%(5 / 69)$ \\
Middle-age & $71.4 \%(15 / 21)$ & $23.8 \%(5 / 21)$ & $4.8 \%(1 / 21)$ \\
Old & & & \\
Vehicle type & $79.5 \%(54 / 68)$ & $17.6 \%(12 / 68)$ & $2.9 \%(2 / 68)$ \\
Bicycle-style electric-bike & $48.8 \%(21 / 43)$ & $34.9 \%(15 / 43)$ & $16.3 \%(7 / 43)$ \\
Scooter-style electric-bike & $67.6 \%(75 / 111)$ & $24.3 \%(27 / 111)$ & $8.1 \%(9 / 111)$ \\
\hline Overall &
\end{tabular}


Table 3 presents the observation of NYLS riders, AYLS riders, and CYLS riders being 75, 27, and 9, respectively. A majority of observed YLS riders had NYLS behaviours $(67.6 \%)$, which indicated that upon facing the countdown green-light indications, most of e-bikers decided to smoothly decelerate until stopped behind the stop mark. When they observed the onset of countdown green light, 33 riders changed their stop-go decisions at least once time. The Pearson chi-square test was applied to identify whether there were significant differences in the number of YLS types among different groups. There was statistically significant difference in the number of different YLS types in the gender group $(p<0.01)$, as well as in age group $(p<0.05)$. Most of female e-bikers were more likely to decide decelerating until stopped without changing their stop-decision (76.2\%), while over $40 \%$ of male e-bikers did a two-step or a multiple-step stop-go decision after the onset of countdown green light. Further, YLS riders within middle-age and old groups were more likely to do NYLS behaviour than that of young group (78.3\% and $71.4 \%$ vs. $28.6 \%)$. A large percentage of young riders (i.e., $57.1 \%+14.3 \%=74.1 \%$ ) decided to stop after the onset of countdown green light but modified their decision more than once. However, the number of YLS types had no significant difference in different vehicle types group $(p>0.1)$.

4.2. Descriptive Statistics of e-Bikers' Approaching Speed and Critical Crossing Distance. Approaching speed is a crucial factor related to YLR behavior as mentioned above. The YLR and YLS e-bikers' AS at the beginning of amber light is presented in the cumulative frequency curve as shown in Figure 6. The average AS of YLR e-bikers was $16.5 \mathrm{~km} / \mathrm{h}$, which was less than $25 \mathrm{~km} / \mathrm{h}$ that is the limit speed of e-bike based on the China Road Safety Law [4]. And the average AS of YLS e-bike riders was $11.83 \mathrm{~km} / \mathrm{h}$ at the beginning of amber light. The result of independent sample Student's $t$ test indicated that the AS of YLR and YLS e-bikers had significant difference $(F=3.387, p<0.01 ; t=5.848, p<0.01))$ and that the AS of YLR riders was significantly higher than that of YLS ones.

Further, the AS of different YLR types was analyzed by Levene's test prior to the Student $t$-test. The result showed that the AS of different types for YLR and YLS e-bikers was significantly different at the level of 0.01 . As indicated in Figure $7(\mathrm{a})$, the NYLR riders had an average AS of $17.03 \mathrm{~km} /$ $h$ with a standard deviation of $6.43 \mathrm{~km} / \mathrm{h}$ which was higher than that of AYLR e-bikers $(M=9.40 \mathrm{~km} / \mathrm{h}, \mathrm{SD}=3.90 \mathrm{~km} /$ h). The one-way ANOVA results showed that the AS of different types for YLS riders had significant difference $(F=21.307, p<0.001)$. A post hoc test, using Least Significant Difference (LSD) method, revealed that the AS for AYLS was significantly higher than that of NYLS and CYLS riders $(p<0.001)$, but there was no significant difference of the AS between NYLS and CYLS riders $(p=0.106)$ (see Figure 7(b)).

e-bike riders' critical crossing distance at the beginning of amber light also has significant impact on riders' decision of YLR behaviour. Based on the data we extracted from the videos, sample e-bikes of AS and CCD for different types of YLR and YLS at the beginning of amber light were indicated by the solid plots in Figure 8. It was found that the e-bikers could make different stop-go decisions, even a contrary decision with similar AS and CCD from this figure which showed the complexities of the riders' stop-go decision.

For the purpose of comparison, the independent sample Student $t$-test was used to analyze the CCD for YLR and YLS groups' e-bikers. The CCD were significantly different between YLR group and YLS group $(F=46.658, p<0.001 ; t=12.2, p<0.001)$. The YLR e-bikers were closer to stop mark than YLS ones at the beginning of amber light (6.29 $\mathrm{m}$ vs. $14.24 \mathrm{~m})$. By applying Student's $t$-test, we compared the values of CCD for different YLR types. The results of tests indicated that the CCD of different YLR types were significantly different at the level of 0.01 . NYLS riders were closer to stop mark than AYLS riders $(5.93 \mathrm{~m}$ vs. $11.06 \mathrm{~m})$, as shown in Figure 9(a). A one-way ANOVA test was carried out and the significant difference can be observed from the result for the CCD in different YLS types $(p<0.001)$. Using LSD method, the result of post hoc test revealed that NYLS riders was the farthest from the stop mark than AYLS and CYLS riders $(p<0.001)$. And the CCD for the CYLS riders was significantly closer to stop mark than that of AYLS riders at the beginning of amber light $(p<0.001)$ (see Figure 9(b)).

4.3. Modeling Result. Both base logit model (BLM) and random parameter logit model (RPLM) were established to identify and evaluate the contributing factors on the e-bikers' YLR infringement. WinBUGS software developed by the University of Cambridge was used to estimate these models. Table 4 presents the final results from two developed models (i.e., BLM and RPLM). In RPLM, the standard deviations were included for those parameter estimates which were observed to vary across individual riders.

Also, AIC was used to compare the goodness of fit of these two models. It is noteworthy that the RPLM provided a statistically superior fit relative to the BLM as indicated by the AIC value of RPLM smaller than that of BLM (1071.4 vs. 1336.3), shown in Table 5.

\section{Discussion}

The objective of our study was to analyze the contributing factors to e-bikers' YLR behaviour at signalized intersection. Owing to the lack of risk perception and safety riding awareness, traffic signal violation, especially YLR behaviour, is common in e-bikers' crossing behaviour in China. In our study, the natural observation results showed that $63 \%$ of e-bikers had a YLR violation when they arrived at intersection facing signal change interval, which is slightly lower than the result proposed by Bharat [13] (the proportion of YLR violation was $68.6 \%$ in motorized two wheel). However, the proportion of YLR e-bikers is relatively higher than the result reported by Tang et al. [31] (the proportion of the GR near-violation, also called YLR violation, was 32\%). The difference between these two studies may be caused by the 


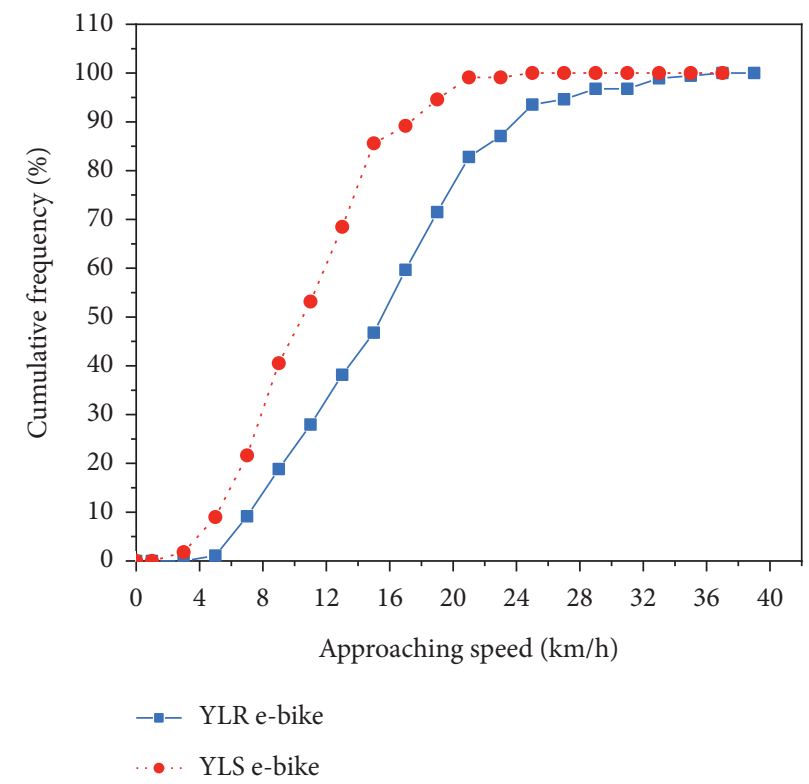

FIGURE 6: Cumulative frequency curve of approaching speed for YLR and YLS e-bike.

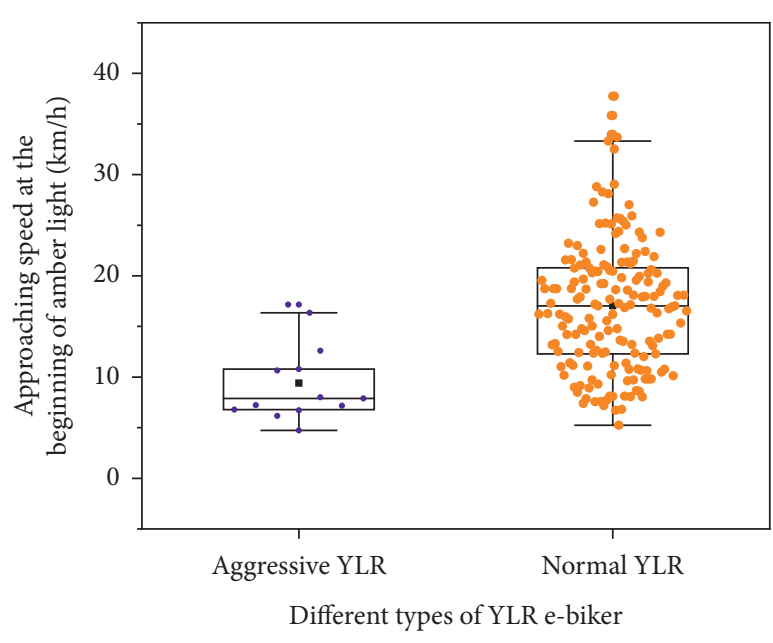

(a)

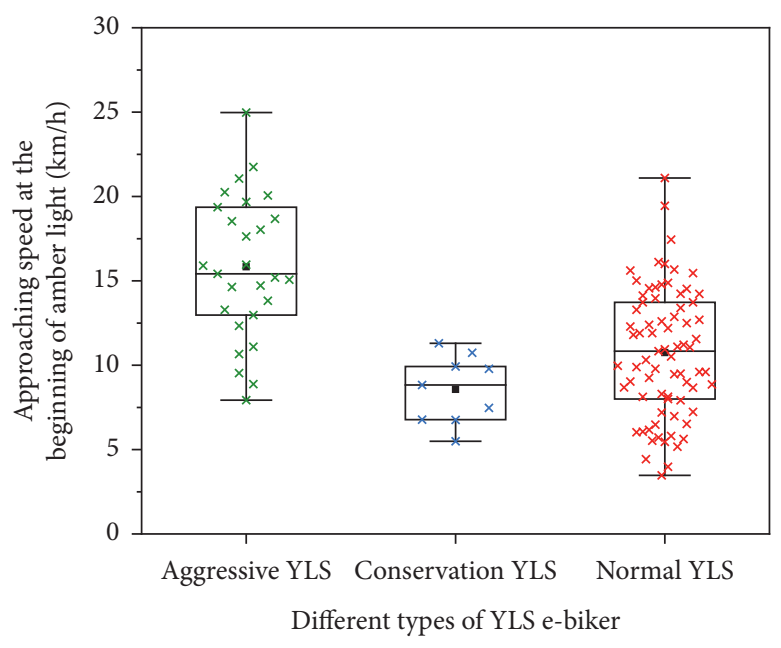

(b)

FIGURE 7: Box plots of approaching speed for different types of YLR and YLS e-bikers.

different data collection process, which is that we only collected the e-bike riders' crossing behaviour who faced the signal change interval, while in Tang's study the authors recorded all e-bike riders' crossing behaviours during peak hours.

Two logistics regression models (i.e., BLM and RPLM) were applied to test the factors which affected e-bikers' YLR behaviour. Given that the RPLM outperforms the BLM (the value of AIC in RPLM model is smaller than that of BLM), we selected RPLM for evaluating the contributing factors on e-bikers YLR behaviour. e-bikers' gender, age group, and the operation attributes including AS, CCD, and NA were found to have significant effects on YLR behaviour. To analyze the effects of these contributing factors on the likelihood of infringement behaviour, the odds ratio (OR) was used. The
OR could be defined as the effect of a one-unit increase in a contributing factor to the odds of YLR violation with other factors being controlled for.

5.1. Analysis of Approaching Speed. As mentioned above, results from Student's $t$-test and the one-way ANOVA model implied that riders' AS was significantly different in different types of YLR and YLS behavior. The AS of NYLR was higher than that of AYLR, indicating that the NYLR e-bikers decided to pass through the stop mark without any decelerating. On the other hand, the lowest value of AS was observed in CYLS e-bikers who changed their stop-go decision more than 2 times. As shown from the result of RPLM in Table 4, AS was found to be significant associated with 


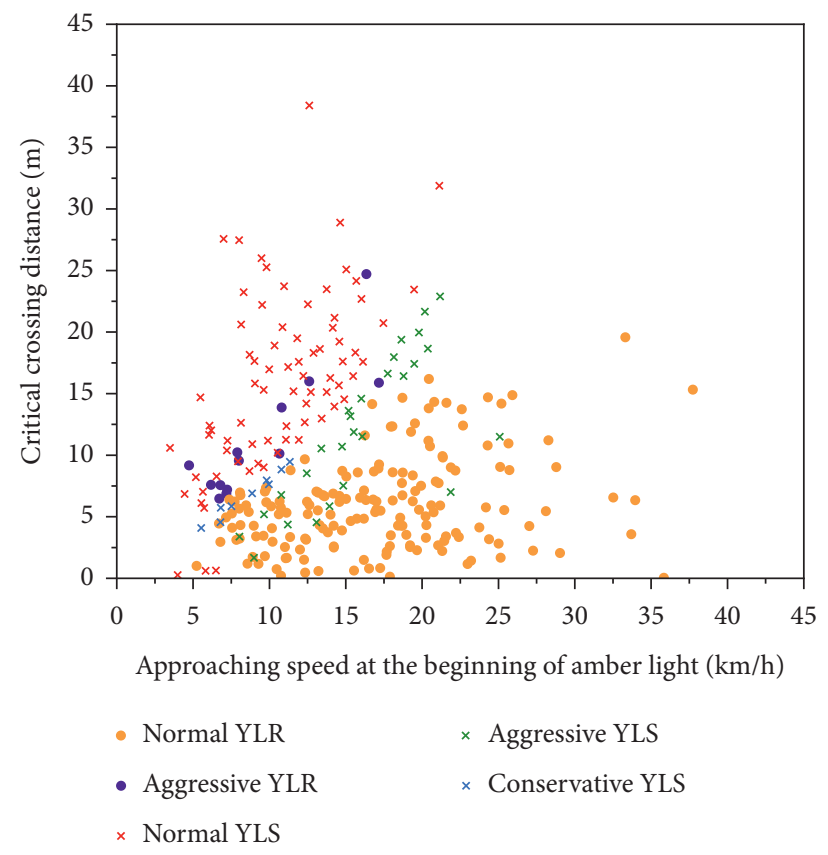

Figure 8: Stop-go decision types in the AS-CCD diagram.

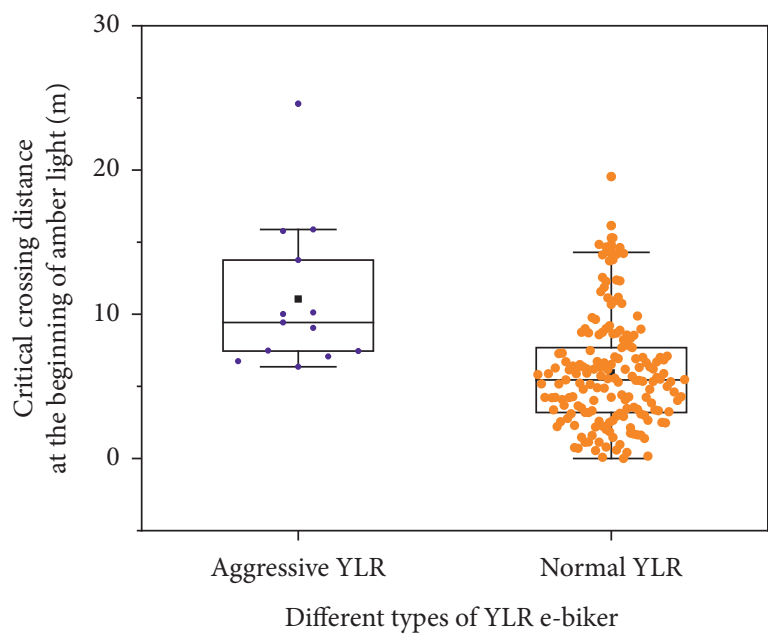

(a)

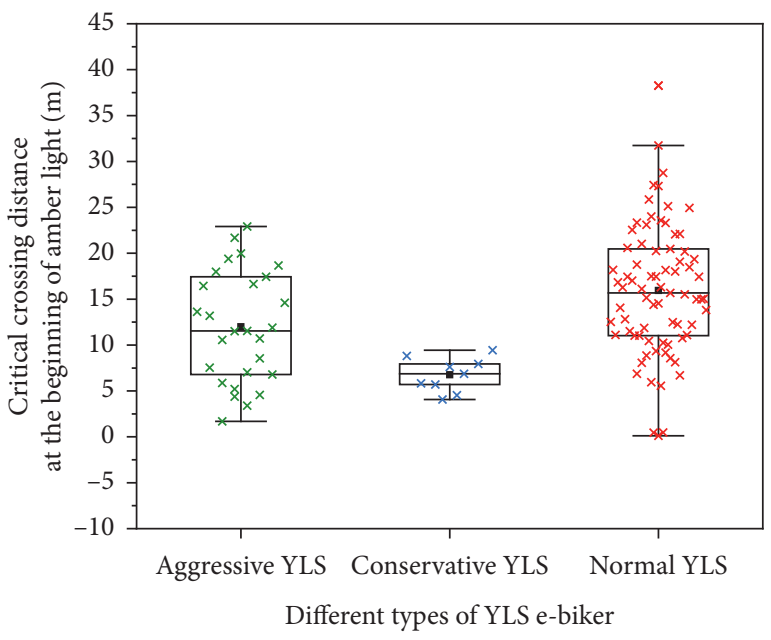

(b)

FIgURE 9: Box plots of critical crossing distance for different types of YLR and YLS e-bikers.

e-bikers' YLR behavior. The RPLM illustrated that the value of OR was $1.53\left(\mathrm{e}^{0.427}\right)$. This value was indicated that when the e-biker was riding $1 \mathrm{~km} / \mathrm{h}$ (one unit) faster than others, he/she would have 1.53 times to do a YLR behaviour. This finding was consistent with previous studies that the larger the e-bike and motorcycles approaching speed had, the higher the probability of YLR was in the drivers' crossing behaviour $[13,30]$. The result in e-bike vehicles was also in accord with previous researches on motor vehicle YLR violation [11-13]. The parameter for AS was a normal distribution with a mean of 0.427 and a standard deviation of 0.688 . According to the cumulative probability function of the AS distribution, the figures suggested that $72.9 \%$ samples were greater than 0 and $27.1 \%$ samples were less than 0 . This demonstrated that the effect of AS on $72.9 \%$ of samples was positive which indicated that the probability of YLR behavior increased. On the other hand, the effect of AS on $27.1 \%$ of samples was negative which indicated that the probability of YLR behavior decreased. The approaching speed of e-bike was a significant predictor to predict the YLR violation, which may be caused by the fact that motorcyclists who regarded themselves as "speeder" were more likely to run against signal $[47,48]$.

5.2. Analysis of Critical Crossing Distance. YLR could be caused by that amber light time is not long enough for e-bike to cross through stop mark before the signal indication turns to 
TABLE 4: Estimates of parameters in BLM and RPLM for e-bikers' YLR behaviour.

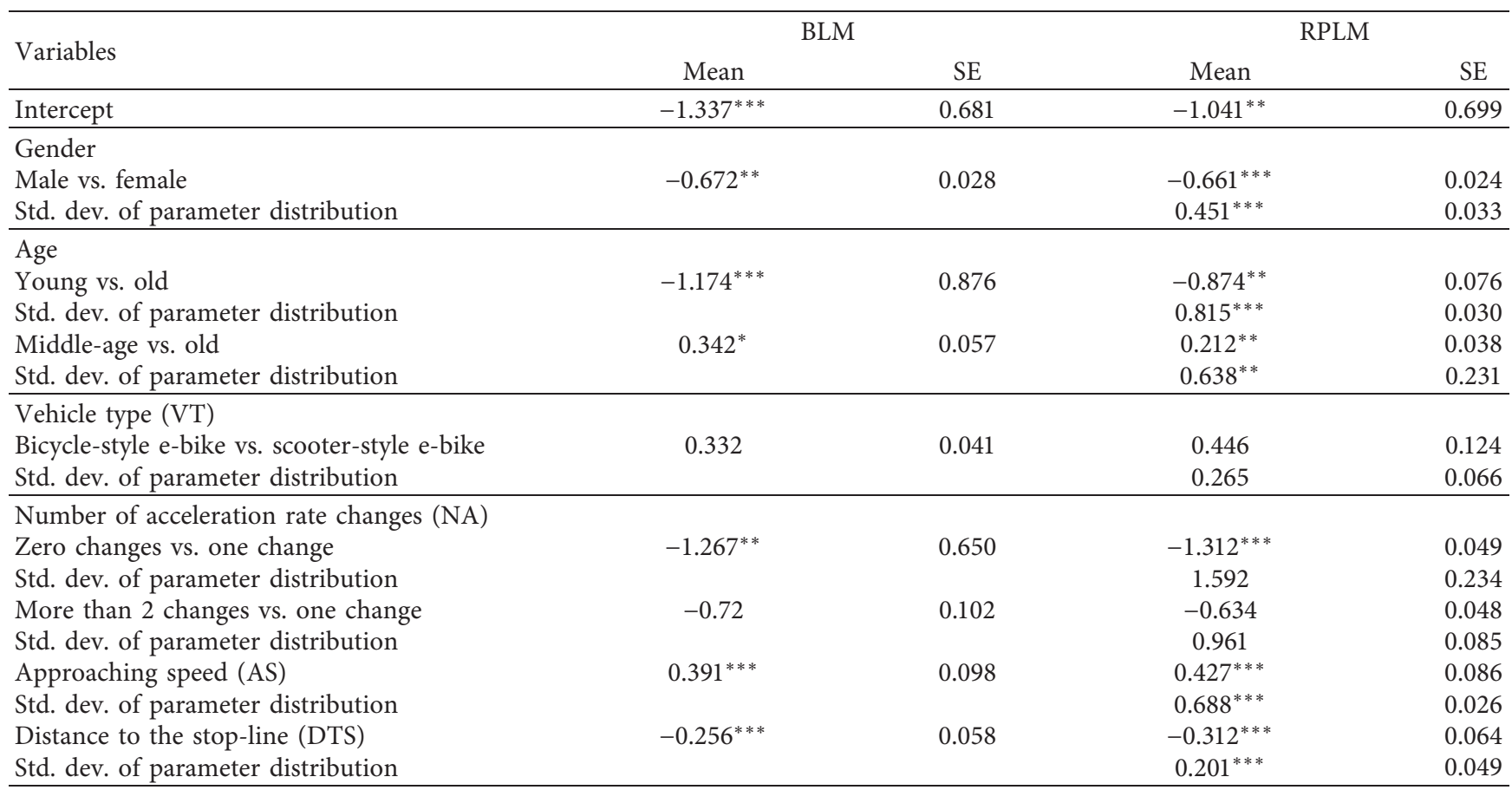

${ }^{*}$ Statistically significant at $\alpha=0.10 .{ }^{* *}$ Statistically significant at $\alpha=0.05 .{ }^{* * *}$ Statistically significant at $\alpha=0.01$.

TABLE 5: Goodness-of-fit measures for BLM and RPLM.

\begin{tabular}{lcc}
\hline & BLM & RPLM \\
\hline Number of observations & 297 & 297 \\
Log-likelihood at zero, LL(0) & -511.13 & -501.59 \\
Log-likelihood at convergence, LL $(\beta)$ & -661.02 & -486.71 \\
Akaike Information Criterion (AIC) & 1336.3 & 1071.4 \\
\hline
\end{tabular}

red; therefore, critical crossing distance at the beginning of amber light is an important indicator for intersection safety. Based on the results we analyzed above, the average value of CCD for NYLR riders was the smallest than other observed e-bikers at the beginning of amber light, which means that NYLR riders were close to stop mark at the beginning of amber light. Thus, they would be confident with the enough time in which they can cross the stop mark safely without waiting next green light. But it is also true that the AYLR riders who had a longer CCD had YLR behaviour. This may explain the random effects of CCD on e-bikers' YLS behaviour as suggested by the estimated parameters with a mean of -0.312 and a standard deviation of 0.201 . The results indicated that the effect of CCD on the YLR was negative and was in line with some previous studies in which the researchers concluded that drivers who drove close to the stop mark had higher likelihood to run against traffic signal in signal change interval $[8,13,30]$.

5.3. Analysis of the Number of Acceleration Rate Changes. Due to the low power output, the acceleration rate or deceleration rate, which also can be seen as the e-bike riders' stop-go decision, was the most critical factor affecting the speed of e-bike. With regard to the number of acceleration rate changes for e-bikers, consistent with the study proposed by Tang [31], the e-bikers who could know the remaining time of amber light from the countdown timer are more likely to accelerate to clear the intersection. e-bikers who decided not to change their initial acceleration rate (keep accelerating to pass the stop line) were found to have YLR violation with the probability of $271 \%$ higher than the riders who change their initial decision once time. Similar findings that vehicles would change speed to cross the intersection were reported in many researches $[24,49,50]$. In natural observation, e-bike riders could assess the viability of passing through the stop mark based on the environment constraints and the acceleration rate of their e-bike. The number of YLR riders who decided not to change their initial accelerating behaviour was much more than that number of YLR riders who had changed their acceleration once time. However, the second dummy variable's effect on YLR behaviour was not statistically significant. The result could be caused by the fact that there were no riders who repetitively changed their stop-go decision, which also can be seen as acceleration rate changed more than 2 times, and had YLR behaviour in our natural observation.

5.4. Analysis of e-Bikers' Characteristics. The crucial explanatory variable gender has negative effect on e-bikers' YLR violation. Compared to male, female e-bikers were 
found less likely to have YLR behaviour with a mean of -0.661 and a standard deviation of 0.451 . The figures of cumulative probability function implied that $7 \%$ of female e-bikers tended to run against the amber light indications despite the decreased probability of YLR behaviour for the majority of female. The result was consistent with the findings proposed by previous researches. For example, female drivers including e-bikers and motors drivers are found to be less likely to be involved in YLR behaviour $[4,9,10,17]$. In addition, other studies have found that male e-bikers have more propensity to disobey traffic rules $[20,25,31]$. The female drivers are more prone to obey the traffic regulation [51] and have higher level of risk perception [52], which mean that female drivers were more cautious than the male drivers in risky driving situations. The higher violation of male driver may be caused by human or physiological factors. The research developed by Parker et al. suggested that facing the traffic light changes, males would react more angrily and aggressively in driving than female drivers. The male riders would not tolerate to wait the next green-light; therefore, they are prone to infringe the traffic regulation. And males are more likely to engage in risky behaviours (i.e., traffic light violation) [53].

e-bikers' age was found to be significantly related to riders' YLR behaviours. The estimated age group was a threecategory variable; two dummy variables were set for BLM and RPLM as mentioned above. The effect of the first dummy variable was with a mean of -0.874 and a standard deviation of 0.815 , which meant that the old-age riders were 0.42 times less likely to run against the amber light than the young-age individuals. Given the distribution, $86 \%$ of the distribution was below 0 , while $14 \%$ of distribution was above 0 . This implied that most old e-bikers (86\%) were less prone to have YLR behaviour, and a minority of old-aged (14\%) had a higher probability to do YLR. This tied with the previous studies proposed by Bernhoft and Carstensen [54] and Chung and Zamani $[55,56]$ in which the authors found that young-age drivers have more propensity to engage in risky driving behaviours and involve in severe accidents. In contrast, old riders appeared to have an opposite tendency compared to middle-age riders. The old riders were more likely to be involved in YLR behaviour. The indicator variable for the second dummy variable leads to a random parameter with a mean of 0.212 and a standard deviation of 0.638 , suggesting that $62.9 \%$ of old e-bikers had an increased probability to have YLR behaviour while the remaining old individuals (37.1\%) were less likely to run against the amber light indication. This result reflected the heterogeneity of old e-bikers. However, this finding was inconsistent with $\mathrm{Wu}$ [57] and Feng [58], which concluded that middle-age riders have higher probability to have aberrant driving behaviors than other drivers.

In terms of vehicle type, the rate of YLR for bicycle e-bike was $16.8 \%(50 / 297)$ and the rate for scooter e-bike was $45.8 \%$ $(136 / 297)$. Despite the different rate of YLR for two different vehicle types of e-bike, the vehicle type's effect on e-bike YLR was not significant according to the result of RPLM. This may be caused by that although e-bikers ride different types of e-bike, they tend to have similar behaviours in same cycling environment. This finding was similar with the conclusion that the bicycle riders and e-bike riders do not have significant impact on the immediate RLR behaviours [24].

\section{Conclusions}

To improve the intersection safety under mixed traffic condition, especially under fully autonomous driving condition in the near future, we have found out factors contributing to e-bikers' stop-go decision to cross through stop mark during the signal change interval. Using a UAV and a synchronized camera, high-resolution videos of e-bikers' stop-go decision-making process in the signal change interval were obtained. We identified 297 cases for e-bikers' crossing behaviour during amber light period. Two analytical models including a base logit model and a random parameter logit model were established based on the e-bike individuals' characteristic data, i.e., gender, age group, vehicle type, and the operations characteristic data, i.e., the approaching speed, the critical crossing distance, and the number of acceleration rate changes to investigate the relationship between explanatory variables and the e-bike YLR violation. Accordingly, several key conclusions can be made as follows:

(1) In order to increase the accuracy of predicting e-bikers' YLR violation and to better understand the e-bikers' decision-making process, we believe the further classification of the e-bikers is essential. YLR riders should be categorized into NYLR and AYLR, whereas YLS individuals ought to be divided into NYLS, AYLS, and CYLS. Based on the statistical analysis, the conclusions indicate that the AS and CCD are significantly different for different types of YLR and YLS cases. Concretely, the AS for NYLR riders is higher than that of AYLR; nevertheless, the CCD of AYLR is larger than that of NYLR. AYLS e-bikers' AS is significantly faster than the other two types of YLS individuals, yet they are closer to the stop mark than NYLS e-bikers.

(2) We recommend to adopt RPLM as the prediction model for e-bikers' YLR violation since the value of AIC showed the statistical superiority of the RPLM compared to the BLM. Also, taking unobserved heterogeneities effects into consideration could improve the prediction probability of e-bikers' YLR behaviours.

(3) By taking additional factors, such as approaching speed, critical crossing distance, and especially the number of acceleration rate change into account, our proposed estimation model can more accurately predict probability of the traffic rules violation based on e-bike drivers' behaviours before the beginning of the amber light. For instance, e-bikers who have the higher AS, shorter CCD and do not change their initial acceleration rate would increase their probabilities to run against the amber light. In addition, female and middle-age e-bikers are less likely to have YLR behaviours. 
Although this study provided insights into e-bike riders' YLR behaviour, there are some limitations should be done in further works. Firstly, the data was only collected in a fourleg intersection which may not reflect general environment of intersections. Secondly, the observation was conducted on individual e-biker. The objective e-bikers are not linked with other riders which may ignore the impact of platoons. Last but not least, the dataset we used is only including limited samples; thus, we encourage other researchers to test our approach on their larger dataset. Future works should take more observations and the effects of platoons into consideration to validate the findings of our study.

\section{Data Availability}

The data used to support the findings of this study have not been made available due to data privacy.

\section{Conflicts of Interest}

The authors declare that there are no conflicts of interest with respect to the research, authorship, and/or publication of this article.

\section{Acknowledgments}

This work was supported in part by the National Key Research and Development Program of China under Grants 2017 YFC0803900 and 2018YFC0807500, in part by the National Natural Science Foundation of China under Grants U1664264 and 51878066, in part by the Central Universities and Colleges of Chang'an University under Grant 300102229201, and in part by Henan Provincial Science and Technology Foundation under Grant no. 2019G-2-11.

\section{References}

[1] S. Das and A. K. Maurya, "Modelling of motorised twowheelers: a review of the literature," Transport Reviews, vol. 38, pp. 1-23, 2018.

[2] A. N. Stephens, J. Brown, L. De Rome, M. R. J. Baldock, R. Fernandes, and M. Fitzharris, "The relationship between motorcycle rider behaviour questionnaire scores and crashes for riders in Australia," Accident Analysis \& Prevention, vol. 102, pp. 202-212, 2017.

[3] K. Schleinitz, T. Petzoldt, S. Kröling, T. Gehlert, and S. Mach, " $(E-)$ cyclists running the red light-the influence of bicycle type and infrastructure characteristics on red light violations," Accident Analysis \& Prevention, vol. 122, pp. 99-107, 2018.

[4] J. Cai, J. Zhao, J. Liu, K. Shen, X. Li, and Y. Ye, "Exploring factors affecting the yellow-light running behavior of electric bike riders at urban intersections in China," Journal of Advanced Transportation, vol. 2020, Article ID 8573232, 12 pages, 2020 .

[5] Z. Wang, R. Neitzel, X. Xue, W. Zheng, and G. Jiang, "Awareness, riding behaviors, and legislative attitudes toward electric bikes among two types of road users: an investigation in Tianjin, a municipality in China," Traffic Injury Prevention, vol. 20, pp. 72-78, 2019.

[6] A. Jahangiri, H. Rakha, and T. A. Dingus, "Red-light running violation prediction using observational and simulator data," Accident Analysis \& Prevention, vol. 96, pp. 316-328, 2016.
[7] C. Wu, L. Yao, and K. Zhang, "The red-light running behavior of electric bike riders and cyclists at urban intersections in China: an observational study," Accident Analysis \& Prevention, vol. 49, pp. 186-192, 2012.

[8] D. Gazis, R. Herman, and A. Maradudin, "The problem of the amber signal light in traffic flow," Operations Research, vol. 8, no. 1, pp. 112-132, 1960.

[9] P. Papaioannou, "Driver behaviour, dilemma zone and safety effects at urban signalised intersections in Greece," Accident Analysis \& Prevention, vol. 39, no. 1, pp. 147-158, 2007.

[10] A. Amer, H. Rakha, and I. El-Shawarby, "Agent-based behavioral modeling framework of driver behavior at the onset of yellow indication at signalized intersections," in Proceedings of the 2011 14th International IEEE Conference on Intelligent Transportation Systems (ITSC), Washington, WA, USA, October 2011.

[11] G. Lu, Y. Wang, X. Wu, and H. X. Liu, "Analysis of yellowlight running at signalized intersections using high-resolution traffic data," Transportation Research Part A: Policy and Practice, vol. 73, pp. 39-52, 2015.

[12] H. Köll, M. Bader, and K. W. Axhausen, "Driver behaviour during flashing green before amber: a comparative study," Accident Analysis \& Prevention, vol. 36, no. 2, pp. 273-280, 2004.

[13] B. K. Pathivada and V. Perumal, "Analyzing dilemma driver behavior at signalized intersection under mixed traffic conditions," Transportation Research Part F: Traffic Psychology and Behaviour, vol. 60, pp. 111-120, 2019.

[14] S. Biswas and I. Ghosh, "Modeling of the drivers' decisionmaking behavior during yellow phase," KSCE Journal of Civil Engineering, vol. 22, no. 11, pp. 4602-4614, 2018.

[15] M. M. Haque, A. D. Ohlhauser, S. Washington, and L. N. Boyle, "Decisions and actions of distracted drivers at the onset of yellow lights," Accident Analysis \& Prevention, vol. 96, pp. 290-299, 2016.

[16] J. Li, X. Jia, and C. Shao, "Predicting driver behavior during the yellow interval using video surveillance," International Journal of Environmental Research and Public Health, vol. 13, no. 12, p. 1213, 2016.

[17] H. Rakha, I. El-Shawarby, and J. R. Setti, "Characterizing driver behavior on signalized intersection approaches at the onset of a yellow-phase trigger," IEEE Transactions on Intelligent Transportation Systems, vol. 8, no. 4, pp. 630-640, 2007.

[18] T. Campisi, G. Tesoriere, A. Canale et al., "Comparison of redlight running (RLR) and yellow-light running (YLR) traffic violations in the cities of Enna and thessaloniki," Transportation Research Procedia, vol. 45, pp. 947-954, 2020.

[19] P. T. Savolainen, "Examining driver behavior at the onset of yellow in a traffic simulator environment: comparisons between random parameters and latent class logit models," Accident Analysis \& Prevention, vol. 96, pp. 300-307, 2016.

[20] L. Bai, P. Liu, Y. Guo, and H. Yu, "Comparative analysis of risky behaviors of electric bicycles at signalized intersections," Journal of Crash Prevention \& Injury Control, vol. 16, pp. 424-428, 2014.

[21] X. Yang, M. Huan, M. Abdel-Aty, Y. Peng, and Z. Gao, “A hazard-based duration model for analyzing crossing behavior of cyclists and electric bike riders at signalized intersections," Accident Analysis \& Prevention, vol. 74, pp. 33-41, 2015.

[22] H. Yang, X. Liu, F. Su, C. Cherry, Y. Liu, and Y. Li, "Predicting e-bike users' intention to run the red light: an application and extension of the theory of planned behavior," Transportation 
Research Part F: Traffic Psychology and Behaviour, vol. 58, pp. 282-291, 2018.

[23] T. Tang, H. Wang, X. Zhou, and H. Gong, "Understanding electric bikers' red-light running behavior: predictive utility of theory of planned behavior vs prototype willingness model," Journal of Advanced Transportation, vol. 2020, Article ID 7097302, 2020.

[24] W. Wang, Z. Yuan, Y. Liu, X. Yang, and Y. Yang, "A random parameter logit model of immediate red-light running behavior of pedestrians and cyclists at major-major intersections," Journal of Advanced Transportation, vol. 2019, Article ID 2345903, 2019.

[25] H. Mei, X. Yang, and B. Jia, "Crossing reliability of electric bike riders at urban intersections," Mathematical Problems in Engineering, vol. 2013, Article ID 108636, , 2013.

[26] F. Yan, B. Li, W. Zhang, and G. Hu, "Red-light running rates at five intersections by road user in Changsha, China: an observational study," Accident Analysis \& Prevention, vol. 95, pp. 381-386, 2016.

[27] R. Yu, H. Zhao, C. Zhang, and Z. Wang, "Analysis of risktaking behaviors of electric bicycle riders in response to pedestrian countdown signal devices," Traffic Injury Prevention, vol. 20, no. 2, pp. 1-7, 2019.

[28] Y. Zhang and C. Wu, "The effects of sunshields on red light running behavior of cyclists and electric bike riders," Accident Analysis \& Prevention, vol. 52, pp. 210-218, 2013.

[29] K. Tang, S. Dong, F. Wang, Y. Ni, and J. Sun, "Behavior of riders of electric bicycles at onset of green and yellow at signalized intersections in China," Transportation Research Record: Journal of the Transportation Research Board, vol. 2317, no. 1, pp. 85-96, 2012.

[30] S. Dong, J. Zhou, and S. Zhang, "Determining E-bike drivers' decision-making mechanisms during signal change interval using the hidden Markov driving model," Journal of Advanced Transportation, vol. 2019, Article ID 7341097, 2019.

[31] T. Tang, H. Wang, J. Ma, and X. Zhou, “Analysis of crossing behavior and violations of electric bikers at signalized intersections," Journal of Advanced Transportation, vol. 2020, Article ID 3594963, 2020

[32] W. Du, J. Yang, B. Powis et al., "Understanding on-road practices of electric bike riders: an observational study in a developed city of China," Accident Analysis \& Prevention, vol. 59, pp. 319-326, 2013.

[33] X. Yang, M. Abdel-Aty, M. Huan, B. Jia, and Y. Peng, "The effects of traffic wardens on the red-light infringement behavior of vulnerable road users," Transportation Research Part F: Traffic Psychology and Behaviour, vol. 37, pp. 52-63, 2016.

[34] J. Li, Q. He, H. Zhou, Y. Guan, and W. Dai, "Modeling driver behavior near intersections in hidden Markov model," International Journal of Environmental Research and Public Health, vol. 13, p. 1265, 2016.

[35] J. Li, B. Jiang, C. Dong, J. Wang, and X. Zhang, “Analysis of driver decisions at the onset of yellow at signalized intersections," Journal of Advanced Transportation, vol. 2020, pp. 1-12, 2020.

[36] L. Zheng, T. Sayed, and Y. Guo, "Investigating factors that influence pedestrian and cyclist violations on shared use path: an observational study on the Brooklyn bridge promenade," International Journal of Sustainable Transportation, vol. 14, no. 7, pp. 503-512, 2020.

[37] T. Zeng, Essays on the Random Parameters Logit Model, Louisiana State University, Baton Rouge, LA, USA, 2011.

[38] F. Chen, S. Chen, and X. Ma, "Analysis of hourly crash likelihood using unbalanced panel data mixed logit model and real-time driving environmental big data," Journal of Safety Research, vol. 65, pp. 153-159, 2018.

[39] B. Dong, X. Ma, F. Chen, and S. Chen, "Investigating the differences of single-vehicle and multivehicle accident probability using mixed logit model," Journal of Advanced Transportation, vol. 2018, pp. 11.11-11.19, 2018.

[40] Y. Guo, Y. Wu, J. Lu, and J. Zhou, "Modeling the unobserved heterogeneity in E-bike collision severity using full bayesian random parameters multinomial logit regression," Sustainability, vol. 11, no. 7, p. 2071, 2019.

[41] F. Chang, P. Xu, H. Zhou, A. H. S. Chan, and H. Huang, "Investigating injury severities of motorcycle riders: a twostep method integrating latent class cluster analysis and random parameters logit model," Accident Analysis \& Prevention, vol. 131, pp. 316-326, 2019.

[42] F. Chen and S. Ma, "Investigation on the injury severity of drivers in rear-end collisions between cars using a random parameters bivariate ordered probit model," International Journal of Environmental Research and Public Health, vol. 16, no. 14, p. 2632, 2019.

[43] Government, C.C. Road Traffic Safety Law of the People's Republic of China. 2011.

[44] Z. Feng, M. Yang, W. Zhang, Y. Du, and H. Bai, "Effect of longitudinal slope of urban underpass tunnels on drivers' heart rate and speed: a study based on a real vehicle experiment," Tunnelling and Underground Space Technology, vol. 81, pp. 525-533, 2018.

[45] W. Zhang, K. Wang, L. Wang, Z. Feng, and Y. Du, "Exploring factors affecting pedestrians' red-light running behaviors at intersections in China," Accident Analysis \& Prevention, vol. 96, pp. 71-78, 2016.

[46] P. C. Anastasopoulos and F. L. Mannering, “An empirical assessment of fixed and random parameter logit models using crash- and non-crash-specific injury data," Accident Analysis \& Prevention, vol. 43, no. 3, pp. 1140-1147, 2011.

[47] K. Chorlton, M. Conner, and S. Jamson, "Identifying the psychological determinants of risky riding: an application of an extended theory of planned behaviour," Accident Analysis \& Prevention, vol. 49, pp. 142-153, 2012.

[48] M. A. Elliott, "Predicting motorcyclists' intentions to speed: effects of selected cognitions from the theory of planned behaviour, self-identity and social identity," Accident Analysis \& Prevention, vol. 42, no. 2, pp. 718-725, 2010.

[49] K. Shaaban, D. Muley, and A. Mohammed, "Analysis of illegal pedestrian crossing behavior on a major divided arterial road," Transportation Research Part F: Traffic Psychology and Behaviour, vol. 54, pp. 124-137, 2018.

[50] C. Havard and A. Willis, "Effects of installing a marked crosswalk on road crossing behaviour and perceptions of the environment," Transportation Research Part F: Traffic Psychology and Behaviour, vol. 15, no. 3, pp. 249-260, 2012.

[51] F. Fraboni, V. Marín Puchades, M. De Angelis, L. Pietrantoni, and G. Prati, "Red-light running behavior of cyclists in Italy: an observational study," Accident Analysis \& Prevention, vol. 120, pp. 219-232, 2018.

[52] K. Wang, W. Zhang, J. Liu et al., "Exploring the factors affecting myopic drivers' driving skills and risk perception in nighttime driving," Cognition, Technology \& Work, vol. 21, no. 2, pp. 275-285, 2019.

[53] C. Wang, W. Zhang, Z. Feng, K. Wang, and Y. Gao, "Exploring factors influencing the risky cycling behaviors of young cyclists aged 15-24 Years: a questionnaire-based study in China," Risk Analysis, vol. 40, no. 8, p. 1554, 2020. 
[54] I. M. Bernhoft and G. Carstensen, "Preferences and behaviour of pedestrians and cyclists by age and gender," Transportation Research Part F: Traffic Psychology and Behaviour, vol. 11, no. 2, pp. 83-95, 2008.

[55] Y.-S. Chung and J.-T. Wong, "Beyond general behavioral theories: structural discrepancy in young motorcyclist's risky driving behavior and its policy implications," Accident Analysis \& Prevention, vol. 49, pp. 165-176, 2012.

[56] F. Zamani-Alavijeh, S. Niknami, M. Bazargan et al., "Risktaking behaviors among motorcyclists in Middle East countries: a case of Islamic Republic of Iran," Traffic Injury Prevention, vol. 11, no. 1, pp. 25-34, 2010.

[57] W. U. Ou and Q. M. Liu, "Electric bicycle related injury and risk factors in hangzhou," Journal of Environmental \& Occupational Medicine, vol. 29, no. 9, 2012.

[58] Z. Feng, J. Zhan, C. Wang, C. Ma, and Z. Huang, "The association between musculoskeletal disorders and driver behaviors among professional drivers in China," International Journal of Occupational Safety and Ergonomics, vol. 26, no. 3, pp. 551-561, 2020. 